\title{
Discussion on Three Topics of Folk Literary Aesthetics
}

\author{
Lili Qin \\ School of Liberal Arts \\ Northwest Minzu University \\ Lanzhou, China
}

\begin{abstract}
Folk literary aesthetics is an interpretation of folk literary and art in aesthetics. This paper studies the forms of folk literary and art from the perspective of aesthetics, and further reveals the special nature and special laws of folk literary and art as an aesthetic activity from the aesthetic aspect of folk literary and art. Therefore, the three topics become the key points, including the nature, aesthetic appreciation direction, specific research objects and content of folk literary aesthetics.
\end{abstract}

Keywords-folk literary aesthetics; aesthetics; aesthetic appreciation

\section{INTRODUCTION}

Folk literary aesthetics is originally an aspect of aesthetic research, and it is embodied in all aspects of people's aesthetic activities, including in the natural phenomena, also in social life and social things. However, the aesthetic activities in literature and art are the most concentrated, perfect, advanced, because literature and art are an aesthetic object created specifically to meet people's aesthetic needs in accordance with the "law of beauty." Taking the entire aesthetic activity of mankind as the research goal of aesthetics, the places wherever an aesthetic relationship exists are listed within the vision of aesthetics. As a branch of folk literature and art, special research on the aesthetic characteristics and aesthetic laws of literature and art is very necessary for folk literary aesthetics.

\section{THE AESTHETIC ORIENTATION OF FOLK LITERARY AESTHETICS}

The aesthetic relationship in aesthetics refers to the aesthetic relationship that is researched in reality. When the aesthetic subject and object form an aesthetic relationship under certain conditions, the aesthetic activity occurs, and in the process of aesthetic activities, both the subject and the object actively and initiatively influence each other and transform into multiple aspects of each other. Aesthetics not only shows the situation to the world, but also gives people a positive, active, and participatory step. It can make people really feel that they are the aesthetic subject, and at this time, aesthetics is no longer an interpretative discipline, but a discipline of behavior, that is to say, aesthetics is not only a static science, but a dynamic science. The aesthetics is originally and actually the aesthetic appreciation, so when we grasp the two keywords of "beauty appreciation", we will truly understand the "origin" and "essence" of "aesthetics", and also we will discover how the "beauty" tracks work by itself. "Aesthetic" reflects the external world, and "appreciation" reflects the true inner emotion and feelings of people.

If there is no external world, there will be no inner feelings of people, and thus the aesthetic reference will be lost, and the true value of "beauty" will not be reflected. The externally existing aesthetic object is an existence of concept, but this existence is potential, therefore, the research of "beauty" is to study the nature, change, existence and disappearance of the object in the subject and object in aesthetic relationship; and the research of "appreciation" is to study the psychology and emotion and mentality of the subject in the subject and object in aesthetic relationship. In fact, it is a cyclical process in which both the subject and the object are mutually converted and attracted to each other under certain conditions, thus the bright and colorful pictures of aesthetic activities are performed one by one. The subject and object of aesthetic appreciation both show their unique literary and artistic works in folk literary aesthetics, which is actually the form of life, embodying the habitat of the human mind.

What is the function of folk literary aesthetics? It can make people feel joyful, recognize the social function and release the emotion, and besides these what function else? If folk literary aesthetics can be completed by itself, is this ability material or spiritual? Is material transformed into spirit, or is spirit transformed into material? Actually these are just the multiple functions of folk literary aesthetics are manifested simultaneously in the aesthetic function, this function is transformed into reality through potential, and this change makes the readers feel their aesthetic attitude and ability.

Generally, the aesthetic activities of the folk literary aesthetics all do more good than harm to people's social life both in form and content, including the satisfaction of people for requirements of social life. However, these functions are not directly expressed, but are transformed after people's subtle influences through accumulation, mutual integration and practice in the social life, and purposed for satisfaction and pleasure of the people. By the study of folk literary and art, we find it has its unique aesthetic law, therefore, we further understand this situation, and we must further study the three links that constitute the activities of folk literary and art, then we can officially get to the specific content and objects of folk literary aesthetics. . 


\section{THE SPECIFIC RESEARCH OBJECTS AND CONTENTS OF FOLK LITERARY AESTHETICS}

The literary and art activities are composed of three parts: creation, works and enjoyment; they have their unique laws, but they can be connected together to become a unified aesthetic activity. The specific object and content of folk literary aesthetics is a unique aesthetic system that consists of three parts: "aesthetics of creation", "aesthetics of works" and "aesthetics of enjoyment". The "art life" of literature and art begins with the creation and is purposed for enjoyment, which is the vivid presentation of the literary aesthetics.

\section{A. Aesthetic Research on the "Creation" of Folk Literature and Art}

The creation of folk literature and art is a unique production process of human spirit, and actually it is a process of literary production as a special "object" from "original sprouting" to "carefully conceiving" and to " successfully producing" by people in their mind, and this whole process of the works creation is the signifying process of revealing the aesthetic implication of literary and artistic works by the writer as a creative subject. Therefore, the process of artistic creation is a process from "original sprouting" to "carefully conceiving" and to "successfully producing", that is to say, the subject is inspired by the external world to have a motive of creation, then the subject and the object meet and integrate, and finally an aesthetic feeling is produced, so to speak that the creation of object by the subject is a combination that the subject transforms the aesthetic feeling into aesthetic image through the artistic conception activities such as choice, fiction, processing and imagination, and at the same time, we can say it is the processing that the subject uses the corresponding external objective world to transform his aesthetic image into a concrete aesthetic image.

Actually, it is a process in which an external society created by a subject and an inner experience integrate and then turn to the external environment. What is the process of transformation telling us? The writer and the reader are concordant with each other, they are the experiencer of each other, and the works of art have vitality. As a spiritual entity, art has no life, but it has vitality and it continues people's feelings about the aesthetic experience in spirit. People often think that the life of a work of art has variability, and no matter whether it is developed and updated or not, they will be replaced by others one by one. The emergence of artistic works is actually a process of alternation of the old by the new, and of innovation, and from this we can see that if we think the art is created based on unique laws, and think it is a unique real substance, can we gasp the art essentially only by trying to discover this unique performance process and discovering its inner potential.

\section{B. What Are the Artistic Aesthetic Characteristics of Folk Literary Aesthetics?}

The artistic aesthetics of folk literary aesthetics is related to its consciousness and sociality, and aesthetics has a special mission and irreplaceable position in literature and art, it should be integrated with society and consciousness, rather than being free from the aesthetics of literature and art, while the image, aesthetic, ration, perception, concrete, abstract, occasionality, inevitability, utilitarian, and non-utility of literature and art all are produced through works of art. Let us imagine that if there is no literature and art in our lives that is closely related to social life, then what is the tone of human life? Only when answering the theoretical questions that how literature and art is developed for art in the human world and how to understand the difference among religion, art and real society, and what are the differences, can we fully grasp the inherent meaning of literature and art, and can we readily solve the puzzle in the aesthetic appreciation of folk literature and art.

\section{The Social Function of Folk Literary Aesthetics}

As a part of folk literature and art, folk literary aesthetics has its own special form of "self-discipline", and folk aesthetics as an aesthetic phenomenon does not appear in the external world alone in a self-protection state. Therefore, it has its form of "heteronomy", and we should further study the aesthetic characteristics and internal relations from the three aspects of creation, works and enjoyment regarding the "heteronomy" of folk literary aesthetics. "Creation - Work Enjoyment" is the three organic connection parts of literary and artistic activities, they all have their unique characteristics and laws, and they are also inseparable for the overall aesthetic activity. Meanwhile, we should make a systematic research on this special aesthetic activity, that is just the content and object of the specific research of folk literary aesthetics, and it is the first task of all disciplines to find the essence through phenomena. All the things that people get through their perception exist in the form of phenomena, and the existence of these phenomena is diverse, hardly dealt with by people, just as now we will think it is inconceivable in the process we study the phenomenon, while when finding the essence of the outside world through the phenomenon, we will achieve an inestimable effect.

For folk literary aesthetics, we should study the literature and art from the perspective of aesthetics, and the most prime purpose is to understand the essence of literature and art through the phenomenon of literature and art. In fact, the things what is called "essence" in literature and art is the main contradiction in the main position of things, just by which, unique changes and laws of development produce. Literature and art are produced through the description of human social life and human thoughts and emotions, and artistic works are regarded as the unity of internal and external things. In art works, there seems to be a "life", just as Susan - Lange says, art can be regarded as a kind of "life form" and the literature and art transform the external world into a virtual art world through aesthetic activities. If literature and art is an active reflection of social life, the aesthetic subject is actually created by the writer through his subjective initiative, so that the literary art is produced. Has the transformation of the artistic works through the author's subjective initiative disappeared? Actually not, when a work of art has a life, the life form created by the writer appears; this feature is actually a subjective form of "self-discipline", which and already possessed the "subject consciousness." as the "product" of literature and art, the literary and artistic activity in aesthetic 
research is a unique creative process, and it can bring a alive art works, which reflects the outside world in a perceptual form, and is active in the spiritual realm of people. Art works is souled, it embodies the external world through its internal life form, and the folk literary aesthetics is thus reflected in the initiative of the creative subject.

\section{CONCLUSION}

The study of literary form in folk literary aesthetics is generally outlined for categories of literature and art, and its purpose is to distinguish the differences among the categories of art in aesthetic characteristics and the difference of aesthetic effects for aesthetic subjects. How to divide the form of folk literature and art, what is the standard and basis, what is the aesthetic characteristic, and what is the special existence mechanism of life form? If we can answer these questions, we will have a further inspiration and exploration for the connotation and extension of folk literary aesthetics.

\section{REFERENCES}

[1] Liu Shouhua, Chen Jianxian. Folk Literature Course [M]. Shanghai: Central China Normal University, 2002. (in Chinese)

[2] Duan Baolin. Summary of Chinese Folk Literature [M]. Beijing: Peking University Press, 2009. (in Chinese)

[3] Wan Jianzhong. Introduction to Folk Literature: 3 [M]. Beijing: Peking University Press, 2006. (in Chinese)

[4] Zhong Jingwen. Zhong Jingwen's Anthology · Folk Literature and Art Volume [M]. Hefei: Anhui Education Press, 2002. (in Chinese)

[5] Dong Xiaoping. Modern Folk Literature and Art Lectures [M]. Guiyang: Guangxi Normal University Press, 2008. (in Chinese)

[6] Duan Baolin. Chinese Folk Literature and Art [M]. Beijing: Culture and Art Publishing House, 2006. (in Chinese) 